\title{
Metáfora e Metonímia segundo a abordagem funcionalista: estudo da gramaticalização do É QUE
}

\author{
Metaphor and Metonymy according to functionalist approach: \\ the study of grammaticalization of the É QUE
}

\section{João Bosco Figueiredo-Gomes \\ Carla Daniele Saraiva Bertuleza}

Universidade do Estado do Rio Grande do Norte Pontifícia - UERN-RN - Mossoró - Rio Grande do Norte - Brasil

\begin{abstract}
Resumo: É crescente o uso falado e escrito da expressão é que dita "expletiva" tanto no português brasileiro quanto no português europeu. Este trabalho consiste num relato dos resultados de uma investigação empírica da emergência da expressão é que. Objetiva apresentar os processo(s)/mecanismos que caracterizam a emergência do uso do é que como relativos a um processo de gramaticalização. No paradigma funcionalista em que se abriga o estudo da gramaticalização, este estudo analisa, diacronicamente, dados amostrais escritos desde o português antigo. Os resultados empíricos parecem comprovar a hipótese de que a trajetória unidirecional de mudança do é que teve, nos estágios iniciais de gramaticalização, uma motivação semânticopragmática da metáfora OBJETO/ESPAÇO > TEXTO; além de um mecanismo metonímico, por meio de uma reanálise do uso original trecentista é o que em é que.
\end{abstract}

Palavras-chave: Funcionalismo. Metáfora. Metonímia. Gramaticalização. É que.

\begin{abstract}
There is a growing spoken and written use of the expression é que named " expletive " both in the Brazilian and European Portuguese. This paper reports the results of an empirical investigation of the emergence use of the expression é que. It aims at presenting the processes/mechanisms that characterize the emergence use of the expression é que as related to a process of grammaticalization. From a functionalist paradigm in which the study of grammaticalization is situated, the study analyzes, diachronically, written sample data since the ancient Portuguese. The empirical results seem to confirm the hypothesis that the one-way path to the change of the expression é que had, in the early stages of grammaticalization a semanticpragmatic motivation OBJECT/ SPACE > TEXT, including a mechanism of metoymy by means of a reanalysis of the 13th century original use of é o que in the expression é que.
\end{abstract}

Keywords: Functionalism. Metaphor. Metonymy. Grammaticalization. É que.Metaphor. 


\section{Introdução}

É crescente o uso falado e escrito da expressão é que dita "expletiva" tanto no português brasileiro quanto no português europeu.

Este artigo consiste num relato dos resultados de uma investigação empírica da emergência da expressão é que. Objetiva apresentar os processo(s)/mecanismos que caracterizam a emergência do uso do é que como relativos a um processo de gramaticalização. No paradigma funcionalista em que se abriga o estudo da gramaticalização, este estudo analisa, diacronicamente, dados amostrais do Corpus Mínimo de Textos Escritos da Língua Portuguesa COMTELPO, organizado por Figueiredo-Gomes e Pena-Ferreira (2006), que reúne textos portugueses do século XII ao século XVIII e textos dos séculos XIX e XX do português do Brasil e do português europeu, classificados segundo o agrupamento de gênero e o período da história do português. Utiliza o programa SPSS para o cálculo de frequência e analisa qualitativamente as construções que, por hipótese, são embrionárias da expressão é que.

$\mathrm{O}$ artigo divide-se em mais duas seções. A primeira abaliza-nos teoricamente sobre os processos e mecanismos envolvidos na gramaticalização, dentre os quais, destacamos, conforme nossos achados, a metáfora e a metonímia; e, por extensão, a analogia e a reanálise. $\mathrm{Na}$ segunda seção, apresentamos 0 percurso diacrônico da expressão é que, demonstrando esses processos e mecanismos flagrados em pontos focais do desenvolvimento da expressão é que.

\section{Processos e mecanismos motivadores da Gramaticalização}

Para o estudo da gramaticalização do é que, adotamos uma concepção funcionalista de que a língua é usada, sobretudo, para satisfazer as necessidades comunicativas. Ela resulta, portanto, da experiência acumulada dos falantes individuais, da sua avaliação do contexto presente, e, principalmente, da interação linguística com seus interlocutores, cujas experiências e avaliações podem ser completamente diferentes.

Devido às assimetrias de suas experiências, falantes e ouvintes negociam e adaptam funções e formas para o sucesso da troca comunicativa, permitindo que a língua altere seus padrões discursivos e sua contraparte mental. Assim, essas negociações e adaptações geram mudanças que, por sua vez, são guiadas por processos e mecanismos que regularizam e fixam seus usos, dentre os quais destacamos a metáfora e a metonímia; e, por extensão, a analogia e a reanálise.

\subsection{Metáfora e Metonímia}

Faz mister o amparo em alguns postulados básicos e, por que não dizer, clássicos do modelo cognitivo do realismo experiencialista, defendidos por Lakoff (1987), Johnson (1987) e Sweetser (1990), para se verificar a motivação cognitiva de base metafórica da gramaticalização, principalmente, segundo Heine et al. (1991).

Segundo Lakoff (1987), os sistemas de conceitos da língua emergem do contato físico-social dos falantes (interação), em sua inserção no mundo real, traduzido por intermédio de metáforas fundantes. Para Johnson (1987), esse sistema conceptual é revelado pela experiência sob forma da metáfora; portanto, é a própria base para a semântica da língua.

Johnson (1987) salienta o processo metafórico como estratégia fundamental para a totalidade da organização conceptual e linguística. Dessa forma, o pensamento inicialmente trabalha com conceitos adquiridos através do contato com o mundo concreto. O sistema conceptual que emerge dessa experiência serve de base para a compreensão de uma realidade mais abstrata que constitui o mundo das ideias. É a metáfora que permite que as pessoas compreendam o mundo das ideias em função do mundo concreto, ou seja, elas compreendem uma coisa como sendo outra, sem confundirem as duas coisas.

Assim as línguas possuem um sistema cognitivo de base experiencial, que opera e determina 
as regularidades que podem ser observadas, na derivação de sentidos e na sua transferência, do domínio real para domínios dos mundos mais abstratos; ou seja, seguem o percurso CONCRETO > ABSTRATO.

$\mathrm{Na}$ perspectiva desse percurso, Sweetser (1990) constrói uma abordagem motivada das regularidades da gramática, de modo a dar conta, de forma unificada, de fatos e procedimentos semânticos diferentes, como a polissemia, mudança semântica lexical e ambiguidade pragmática. Para a autora, a transferência de domínios operada pela metáfora se dá de maneira estável, sistemática e motivada, cumprindo a trajetória unidirecional em três etapas: da fase concreta (realidade físico-social), passando para a abstrata (experiência) e chegando à discursiva. A passagem de uma etapa a outra se faz mediante a transferência metafórica, em que o significado mais abstrato é historicamente derivado do significado físico-social (interacional) imediatamente mais concreto.

A transferência metafórica, segundo Heine et al. (1991, p.43), é um dos principais mecanismos que subjazem ao processo de gramaticalização. Por meio da transferência metafórica, conceitos menos complexos (mais concretos) passam, num processo de abstratização crescente, a conceitos mais complexos (mais abstratos). Então, conceitos que estão mais próximos da experiência humana são utilizados para expressar outros que são mais abstratos: experiência não-física é entendida em termos da experiência física, o tempo em termos de espaço, causa em termos de tempo, relações abstratas em termos de processos cinéticos/relações espaciais etc.

$\mathrm{Na}$ perspectiva da unidirecionalidade, é possível descrever o processo de gramaticalização por meio do arranjo de categorias conceptuais, distribuídas, segundo uma escala de abstração crescente, em que cada elemento conceptualiza um elemento à sua direita num movimento FONTE ALVO, por meio de (>) "flecha(s)", resultando no que os autores chamaram de "metáforas categoriais":
PESSOA > OBJETO > ATIVIDADE > ESPAÇO > TEMPO > QUALIDADE

Cada uma dessas categorias representa uma variedade de conceitos definidos perceptual e/ou linguisticamente, compondo um domínio de conceptualização importante para a experiência humana. Por exemplo, o desenvolvimento do verbo ir pode ser representado por meio do esquema: ATIVIDADE > ESPAÇO > TEMPO, como podemos ver nas amostras (2), (3) e (4):

(2) A gente foi pra festa e.. tinha uma porção de amigos na festa (Daniel - D\&G/RJ)

(3) eu falei...pela primeira vez que eu tô passando nessa rua ((riso)) mas era mentira .... aí ele pegou falou assim "não mas sabe é rapidinho vamos ali tomar uma Coca-Cola"... (Quely - D\&G/RJ)

(4) Eu vou ler o texto (Érica - D\&G/RJ)

Em (1) ir é um verbo pleno com sentido de movimento físico, do latim ire, portanto, [+ concreto]. O uso (2) distancia-se um pouco do uso original (movimento físico), com um sentido de deslocamento para um ponto no espaço, reforçado pelo advérbio ali (movimento espacial), o que deve ter dado origem ao uso com deslocamento no tempo, no caso da amostra (4) que ilustra o futuro analítico.

É essa, pois, a trajetória de ressemantização do verbo ir, que ganhou uma função gramatical. Ao passar para a gramática, esse verbo, principalmente como em (3) e (4), teve sua frequência aumentada no português, segundo Cezário et al. (1996) ao estudar a integração entre cláusulas e o processo de gramaticalização. $\mathrm{O}$ verbo go (ir), em inglês, passou pelos mesmos processos na construção to be going to, que também tem uso de marcador de tempo, como por exemplo: The rain is going to come.(literalmente, "A chuva vai vir."), significando metaforicamente futuridade.

Como vimos, o ir como verbo pleno tem seu sentido original no latim. Para Hopper (1991), as explicações sobre a relação entre uma forma lexical e sua contraparte gramaticalizada em termos de

1 Corpus Discurso \& Gramática/Sigla do Estado. Amostras retiradas de Figueiredo-Gomes (2008). 
metáfora parecem valorizar um método etimológico que compara itens linguísticos removidos do contexto. Cuida que a gramaticalização não deve ser vista do ângulo paradigmático como a substituição repentina de um significado presente no contexto por um ausente - a metáfora, mas, sim, sintagmaticamente, ao ser vista por meio da extensão do significado já implícito nos contextos de uso da forma - metonímia.

O papel da metonímia também tem seu destaque no percurso de gramaticalização, posto que se trata de um mecanismo de mudança cujas motivações estão no contexto linguístico e pragmático de uso de uma dada forma: há uma associação conceitual entre entidades de algum modo contíguas, de forma que o item linguístico que é usado em referência a uma delas passa a ser usado também para outra.

Segundo Traugott e König (1991, p.212), a metonímia envolve a especificação de um significado em termos de outro que está presente no contexto, i. é, representa uma transferência semântica por contiguidade.

À metonímia está ligado um mecanismo chamado por Traugott e König (1991, p.194) de inferência por pressão de informatividade, que designa o processo em que o item linguístico passa a assumir um valor novo, inferido do original, devido à convencionalização de implicaturas conversacionais por meio de pressões do contexto de uso. Quando uma implicação comumente surge com forma linguística, pode ser tomada como parte do significado desta, podendo até mesmo chegar a substituí-lo.

Podemos também aproveitar as amostras (2) a (4), com o verbo ir, para exemplificar também a extensão metonímica, pois, segundo Heine et al. (1991, p.70), o processo cognitivo que envolve a gramaticalização deve ser observado sob duas perspectivas: uma discreta e outra contínua. A primeira é psicológica por natureza e sugere uma análise em termos de metáfora, como exemplificamos; enquanto a perspectiva contínua parece ser essencialmente pragmática, pois é altamente dependente do contexto e exibe uma estrutura metonímica. Então, fazendo uma análise sob essa última perspectiva, as sentenças (2) a (4) sugerem um continuum entre o verbo pleno presente em (2) e a marca de futuridade na amostra (4), com nuanças conceituais minimamente diferenciadas, entre principalmente (2) e (3), por meio do contexto que ainda sugere movimento espacial.

Diferentemente de Heine (1991), há teóricos que defendem tanto a transferência metafórica quanto a transferência metonímica como mecanismos que atuam em diferentes momentos do processo de gramaticalização (BYBEE et al., 1994), ou vinculandose a fenômenos distintos (TRAUGOTT; KÖNIG, 1991), ou tomando partido por um deles. Apesar de existirem essas posições divergentes, há um ponto de concordância em relação aos resultados da atuação desses mecanismos, conjugados ou não, que é a previsão de um percurso de abstração crescente.

\subsection{Analogia e Reanálise}

A analogia e a reanálise são mecanismos ligados aos processos cognitivos da metáfora e da metonímia, respectivamente.

A analogia é um mecanismo que não causa propriamente a mudança linguística, mas a expansão da mudança na língua. Ou seja, estende regras de generalização a itens, atraindo-os para construções já existentes, acarretando a disseminação da inovação para domínios diversos.

A analogia aproxima psicologicamente categorias em ausência, isto é, situadas no eixo paradigmático. Esse processo pode ser captado pela fórmula [ $A$ : $B$ :: C : D], em que D representa a forma surgida por analogia.

Em português, a analogia é usada, por exemplo, para explicar a nasalidade, em português do $\operatorname{sim}$ (< sic, latim), dada sua associação por antonímia com nom. Também estende outros níveis, tais como, no português, o pretérito atual de estar, estive, que é analógico ao pretérito arcaico de ser, sive. Os dois verbos eram usados como locativos, e isto permitiu o trânsito de formas de um para o outro, havendo o desaparecimento do pretérito etimológico arcaico estede (< stedi, latim), e o aparecimento do uso de 
estive por analogia a sive, segundo a fórmula: ser : sive :: estar : estive. É, por exemplo, o que acontece com as tentativas de regularização das crianças ao dizerem eu sabo ao invés de eu sei, ou, mesmo nas regularidades de alguns usos como menos/menas, seja/seje. Trata-se, portanto, da extensão de um uso mais geral para substituir usos menos gerais.

Ao discorrer sobre analogia do português, o lexicógrafo Bueno da Sequeira (1954, p.92) inclui o objeto de análise deste estudo, a expressão é que. Segundo o autor, essa expressão resulta de uma generalização analógica, porque começou a ser usada com um sujeito masculino do singular: "으 homem é o que ofende a Deus.", e, uma vez com o uso generalizado, passou para o feminino do singular: " $\underline{A}$ mulher é a que deve obedecer.", e para o plural dos dois gêneros: "Os homens são os que ofendem a Deus."/ "As mulheres são as que não querem obedecer.". Depois, houve a supressão do demonstrativo, conservando-se a frase no singular, e a expressão se tornou fixa tanto na forma masculina, "Os rebanhos é que fazem a felicidade do campo.", quanto na feminina: " As mulheres é que não querem obedecer.", portanto, invariável.

Dessa forma, Bueno da Sequeira (1954, p.93) supõe que "deve ter influído a existência de três encontros do "é que"”: as expressões enfáticas, nas quais a partícula que, não era pronome, mas conjunção, como em "“É daí que lhe vem toda a graça.' Vieira 2:15", mostrando ao lado do exemplo a inversão: Daí é que e apresenta outro exemplo com o "é que": "Agora é que tinham melhor lugar os desmaios da Esposa.' Vieira 7:46”; o que de uma oração "integrante predicativa": "A maior circunstância que temos dele é que foi no lugar da Parada". "Que foi no lugar da Parada é a maior circunstância. Arcebispo, 2:114" (o autor inverte ao lado para comprovar que se trata de uma predicativa); e, o encontro da locução explicativa é que, correspondente a "razão por que" em latim, ratio quia: "Os carvalhos ... e as boninas não ousam erguê-la (a fronte) para o céu. É que rugindo, a ventania cai da montanha...' Herc., Lendas, 2:106."
Os argumentos e exemplos de Bueno da Sequeira (1954) reforçam a hipótese da analogia envolvida na mudança do é que por nós defendida e demonstrada na seção 2. Vale a pena lembrar que os estudos gramaticais na época baseavam-se tradicionalmente em seguir modelos de exemplos de autores renomados ou de obras literárias, e.g. Vieira, Herculano, e Arcebispo, e não em amostras de uso real. Defendemos que, complementarmente, embora a analogia seja vista como uma generalização de uma regra ou construção, há a atuação da reanálise, já que somente ela pode criar novas estruturas gramaticais. Defendemos a complementaridade na gramaticalização por a analogia provocar a mudança por reanálise ou, em muitos casos, por a analogia ser a primeira evidência para os falantes de uma língua (e também para linguistas como nós) que a mudança ocorreu. (cf. HOPPER; TRAUGOTT, 2003, p. 64).

Hopper e Traugott (2003) afirmam que a analogia pode ser considerada sob duas dimensões: (i) da generalização dos tipos de estruturas linguísticas, e (ii) da generalização por meio do padrão de uso, que, por sua vez, é baseada na frequência com que as estruturas em questão podem ocorrer no tempo.

Segundo ainda Hopper e Traugott (2003, p. 39), a reanálise e a analogia têm sido bastante reconhecidas como significante para a mudança em geral, e mais especialmente para a mudança morfossintática. Segundo os autores, a reanálise modifica as propriedades gramaticais - morfológicas e sintáticas - e as propriedades semânticas, que dizem respeito às mudanças na interpretação, na classificação sintática e no significado e implica mudança de regras. Já, a analogia, estritamente falando, modifica manifestações superficiais e não implica mudança de regra, embora o efeito da regra estenda-se ou no próprio sistema linguístico ou na comunidade. Mas, afirmam que, inquestionavelmente, a reanálise é o mecanismo mais importante para a gramaticalização, como para toda mudança, por ser um pré-requisito para a implementação das mudanças por analogia. 
Então, a reanálise é um mecanismo que consiste na reestruturação de itens ou construções, resultando em uma reinterpretação das relações entre eles. Envolve a reorganização e mudanças, frequentemente locais (e.g. relações entre os constituintes, hierarquia, rótulos categoriais) situadas no eixo sintagmático, mas não implicando nenhuma modificação, intrínseca ou imediata, na manifestação superficial da construção reanalisada. Assim, os falantes mudam de percepção de como os constituintes de sua língua estão inter-relacionados e, por meio do tipo de raciocínio conhecido como abdução, apagam os limites entre esses constituintes, estabelecendo novos "cortes". Como a reanálise não altera imediatamente a unidade sobre a qual se está operando, ela terá consequências futuras, mesmo no eixo sintagmático, posto que uma nova categoria estará surgindo.

Heine et al. (1991, p.215) tomam como exemplo o que Heine e Reh (1984) chamam de reanálise do constituinte interno. Segundo Heine e Reh (1984, p. 104-5), um dos efeitos da gramaticalização é que ela torna constituintes regentes/núcleos em regidos/modificadores. Este processo pode desencadear um desenvolvimento oposto, no tempo, de constituinte regido em um regente. Para os autores, ambos desenvolvimentos envolvem reanálise, mas somente o primeiro envolve gramaticalização. A forma específica do processo mais geral da reanálise, que tem o efeito de redefinir fronteiras de constituinte, torna uma estrutura como [(A,B) C] em uma nova estrutura $[\mathbf{A}(\mathbf{B}, \mathbf{C})]$.

Heine et al. (1991, p. 219) advertem que há, pois, razão para assumir que, embora a gramaticalização e a reanálise pareçam ser gêmeas inseparáveis, elas devem ser mantidas estritamente separadas, pois se, por um lado, a gramaticalização é essencialmente um processo unidirecional, a reanálise não o é, por outro, a gramaticalização não precisa de ser acompanhada pela reanálise.

Entretanto, embora não haja essa dependência, tanto a reanálise quanto a analogia interessam para a gramaticalização. A reanálise implica reorganização linear, sintagmática e, frequentemente, local, e uma mudança de regra, que não é diretamente observável. Por outro lado, a analogia essencialmente implica organização paradigmática, mudança nas colocações de superfície e nos padrões de uso. A analogia faz as mudanças inobserváveis da reanálise observável.

Por fim, a reanálise e a analogia são mecanismos que estão presentes na mudança linguística. Embora eles não definam a gramaticalização, nem sejam, conceitualmente, coextensivos a ela, a gramaticalização não ocorre sem passar por essas etapas, ou seja, por esses processos metafóricos e metonímicos.

\section{Fatores pragmáticos motivadores da gramaticalização da expressão é que}

À guisa do que argumentam Hopper e Traugott (2003), preferimos falar de motivações, tendências e de fatores permissivos/motivadores da mudança linguística, considerando que é possível descrevê-la em termos de mecanismos/processos por que passa, mas nunca tentar apresentar "causas" ou "explicações" no sentido de "predições". Os fenômenos que dão origem à mudança são tão complexos que, até então, é impossível precisar por que uma mudança específica ocorreu no passado ou predizer se ou quando ela ocorrerá (cf. LASS, 1980). Afinal, as mudanças não têm que ocorrer. Contudo, baseamos-nos em fatores potenciais e estatisticamente preferidos.

Dentre as motivações para a mudança, interessa-nos, como funcionalistas, o papel dos falantes e ouvintes negociando significados em situações comunicativas (cf. HOPPER; TRAUGOTT, 2003, p. 71). Então, no estudo de mudanças envolvidas na gramaticalização, acreditamos no relacionamento entre a semântica e a pragmática, apoiados, principalmente, na visão de Levinson (2000), Green (1996), Sperber e Wilson (1986), Hopper e Traugott (2003). Entendemos que a semântica trata dos significados relativamente estáveis fora do contexto (arbitrários) e analisáveis em termos das condições lógicas sob as quais eles 
seriam verdadeiros; já a pragmática, por contraste, trata das crenças e das inferências sobre a natureza de uma suposição feita pelos participantes e os fins para os quais os enunciados são empregados no contexto de uso comunicativo da língua. É importante frisar que, nesses significados, a interpretação do participante-ouvinte tende a enriquecer o que foi dito, a fim de interpretar o que é relevante para o contexto do discurso (cf. HOPPER; TRAUGOTT, 2003, p. 76). Então, nessa visão integrada, semântico-pragmática, uns pensam as mudanças de significados serem motivadas, principalmente, por processo metafóricos, como Claudi e Heine (1986) e Sweetser (1990); outros pensam serem motivadas tanto por processos metafóricos quanto metonímicos, como, por exemplo, Traugott e König (1991) e Heine, Claudi e Hunnemeyer (1991). É na esteira desses últimos que nos posicionamos.

No tocante aos mecanismos que provocam a gramaticalização, destacamos dois mais gerais: primeiramente, segundo os dados desta pesquisa, a analogia, e, secundariamente, a reanálise. Já sobre a motivação, destacamos, como ligadas a esse processo, as motivações semântico-pragmáticas que levam por meio dos processos metafóricos e dos processos metonímicos. Quanto às trajetórias de mudanças, defendemos a unidirecionalidade como princípio que norteia a passagem de itens ou construções lexicais para cumprirem, em certos contextos, funções gramaticais, ou itens gramaticais que desenvolvem novas funções gramaticais.

Partindo da observação da frequência de construções afins (ditas de "clivagem"), presentes no COMTELPO, e da evolução dos três elementos que defendemos estarem envolvidos no processo em estudo, quais sejam: a cópula ser, o demonstrativo e o "que", sintetizamos, a seguir, os achados em quatro estágios por que julgamos terem passado tais elementos para a gramaticalização da expressão é que.

Observando-os, desde o Português Antigo até - Português Moderno, advogamos que a gramaticalização da expressão é que, nos seus estágios iniciais, teve uma motivação por meio da metáfora OBJETO/ESPAÇO > TEXTO. Conceitos espaciais, do "mundo real", são empregados para designar pontos e relações textuais, ou seja, obedecem à tendência translinguística de transição de conceitos concretos para conceitos mais abstratos pertencentes ao mundo do texto.

Essa trajetória inicia-se, pois, a partir do que chamamos de Estágio 0, momento que flagra, ainda no galego-português, como podemos ver na amostra (5), uma plenitude de significado do verbo ser, enquanto verbo existencial; do sintagma nominal intercalado que apresentava localmente o documento indicado pelo demonstrativo de proximidade "Hec" inicial; e do pronome relativo, enquanto conector subordinativo.

(5) Contexto: Início da Notícia de herdades doadas por Pelagius Sueríj

Hec est notitia de heritates quaes ego pelagius sueríj cognomento romue dedi uxori mee sanchia anriquiz, pemominatas/ por suas arras. xij, casales e una quintana.

(Esta é a notícia de herdades que eu, Pelagio Suerij, nome da família de Roma, dei a minha esposa Sanchia Anriquiz, a título de arras, doze casais e uma quinta.) (001.XII.0519-GOP) $)^{2}$

Temos, pois, em (5), o que chamamos de protoconstrução do é que codificada na estrutura Hec est...q.

Já o Estágio 1 flagra essa protoconstrução em frases complexas em uso no Português Antigo, como em (6a), do movimento dos elementos na construção, como em (6b), e do sintagma nominal intercalado com significado mais genérico, que é indicado pelo demonstrativo inicial, que, por sua vez, refere-se, de um modo mais neutro, à porção textual anterior (uma anáfora proposicional), como em (6c).

(6) a. Contexto: Da santa Trindade e da fé católica

[...] e subyo aos ceus en corpo, en dignidade e ende uerrá na cruz en este mundo dar juyzo aos boos e aos maos, e áquel juyzo uerremos todos en corpos en almas e receberemos ben os boos e galardõ de gloria de ben que fezermos por sempre cõ nostro Senhor Ihesu Christo, e os maus rẽceberã pẽa cõ nos maos

\footnotetext{
${ }^{2}$ Número da ocorrência; século; linha; agrupamento de gênero.
} 
dyaboos por sẽpre unde nũqua sayrã. $E$ esta é a nossa fé catholica, que firmemente teemos e cremos. E cuida á fe guardar (e) a eygreya de Roma, que a manda guardar come sacrafiço de nostro Senhor Ihesu Christo, que se faz subello altar pello sacerdote que dereytamente é ordĩado e como do baptismo e dosoutros sacramentos da sancta eygreya. (+)

( $E$ esta é a nossa fé católica que firmemente temos e cremos. (001.XIII.0007-GOA)

b. Contexto: Exposição do ermitão sobre os três touros da visão de Galvão [...] O terceiro, u houvera já sinal de malha, este era Boorz, que peça havia que errara sua virgindade, mas depois o corregeo em guisa que tam bem guardou sua castidade que todo aquel erro foe perdoado. Os três touros eram liados polos corpos: sam estes três cavaleiros que já sam assi liados de humildade que já soberva nom pode a eles entrar. Os outros touros que diziam: << Vaamos buscar milhor pasto que este é $>$, estes sam os companheiros da Távola Redonda que disserom, em dia de Pintecoste: $<<$ Vaamos aa demanda do Santo Graal e seremos avondados das honras no mundo e do manjar celestial que a graça do espírito Santo envia a aqueles que saem aa mesa do santo Graal. [...]

(...são estes três cavaleiros que já são assim ligados pela humildade ... estes são os companheiros da Távola Redonda que disseram no dia de Pentecoste: ) (002.XIII.0126-GOE)

c. Contexto: Como o cavaleiro das armas brancas disse a Galaaz a verdade do escudo [...] - E sabedes que me demanda este escudeiro? Que eu Ihe faça saber a verdade deste escudo e porque tantas maravilhas ende averom aaqueles que, per seu fol ardimento, sobre a defesa de Nosso Senhor o deitarom a seus colos, porque lhes aveem tantas maas andanças como sabem a esta terra. Todo esto me el rogou que lhe eu dissesse, ca nom é direito que o outrem saiba ante que vós. Mas pois vós aqui viestes, eu vo-lo contarei ante ele e ante este irmitam que anda com vosco e que vos contou já ende ũa peça.

- Senhor, disse Galaaz, certas, esto é ũa cousa que eu desejei a saber.

- Pois eu vo-lo direi, disse o cavaleiro, todo assi como aveeo. (010.XIII. 0055-GON)

Nesse Estágio 1, há 0 uso de um demonstrativo catafórico antecipando a referência, ou seja, o documento como objeto concreto, para apresentar o texto e introduzir o conteúdo dele. A cópula ser, como verbo principal, tem a função de identificar ou especificar o sujeito por meio do sintagma nominal predicativo, que, por sua vez, era seguido de uma cláusula relativa, encabeçada pelo pronome que. Chamamos esse primeiro estágio de "pragmático", no sentido de Givón (1979, p.223), ou seja, significando "discurso" ou "uso da construção no discurso". Devido à alta frequência, ou seja, à rotinização da construção, ocorre um fortalecimento pragmático e inicia-se seu percurso de mudança. Então, continuando o processo de mudança, a referência anafórica, ou mesmo catafórica, não se limita só ao OBJETO, mas ao ESPAÇO co-textual ou contextual; apresenta-se, pois, como um demonstrativo invariável, portanto mais abstrato, referindo-se à porção textual anterior (uma anáfora proposicional, não mais uma referência a um sintagma). Ressaltamos que todos esses três elementos tendem, em um bom número de línguas, a gramaticalizar-se.

No Estágio 2, há a evolução do sintagma nominal intercalado para um pronome demonstrativo, resultando na construção clivada $\mathrm{SER}+\mathrm{DEM}+\mathrm{PR}$. O demonstrativo, que, por sua vez, concorda ainda em número e gênero com o sujeito do verbo ser na frase anterior (matriz), é o antecedente da frase subordinada relativa iniciada por "que", como em (7a), (7b) e (7c). Além disso, o pronome demonstrativo ora é substituído por um sintagma nominal, como (7b), ora vem como um determinante demonstrativo, como em (7c), ou ainda conserva sua posição nuclear, tendo um referente anafórico, como em (7d), ou catafórico como na original amostra (5). Em (7d), a construção é o que mostra um uso mais especializado e mais fixo do demonstrativo "o" numa construção típica do que, atualmente, denominam "pseudo-clivada invertida". Trata-se, portanto, de uma construção de clivagem, empregada para focalizar um elemento frasal, no caso "este" (uma informação dada, que se refere anaforicamente a "cavaleiro"), e permitir uma leitura de contraste: "este" (e não outro) é o (= aquele cavaleiro) que dará fim às aventuras do Santo Graal.

(7) a. Contexto: Como os que procuravam as seedas (= cadeiras) as acharam.

$\mathrm{E}$ os que os contarom acharom todas $\mathrm{CL}$ seedas compridas fora duas e disseram-no a 
el-Rei. E el-Rei tendeu as mãos contra o céu, e disse:

- Jhesu Cristo, Padre, Senhor de todalas cousas, beento sejas tu que me leixaste tanto viver a Távola Redonda comprida, que nom falecessem ende fora dous.

Entam disse a aqueles que as seedas haviam de catar:

- Quaes são esses que falecem?

- Senhor, disserom eles, Tristam e a seeda perigosa, que nom é comprida.

(- Quais são esses que faltam?) (003.XIII.0029-GON)

b. Contexto: Tomada de Tavira

(...)e com grandes zemidos e dor os tirarão dantre os moros que jaziaõ os corpos delles lançados no fangue com as elpadas nuas e troucheraõnos á Villa e fizeraõ na melquita mor Igreija de Santa Maria e mandou fazer um moymento em que poz lete elcudos com as vieiras do Senhor Santiago e alli foraõ lobterrados todos feis e o mercador com elles os nomes dos quaes laõ os que le reguem dom Pero Paes commendador mor Mem do Valle, Damião Vaz Alvaro Gracia Eltevaõ Vaz Vallerio de Olla e o mercador Gracia Rodriguez cujos corpos foraõ defpois tidos em grande reliquia ...

(...e ali foram enterrados todos os seis e o mercador com eles os nomes dos quais são os que se seguem $\quad$...) (001.XIII.0092-GOR)

c. Contexto: Descendência de Dom Tello

Este dom Tello foy casado com dona Maria filha do iffamte dom Affomsso de Portugall e de dona Viullamte filha do iffamte dom Manuell e de dona Costamça d'Aragom, e fez em ella dona Isabell. Esta dona Isabell se uê casada com dom Joham Affomsso o boo d'Alboquerque, e fez em ella dom Martinho. Este dom Joham Affomsso foy $\boldsymbol{o}$ que trouuerom no ataúde os iffamtes suso ditos e outros muitos boons como se mostra em este titullo parrafo XII hu está tall sinall. $(+)$

(Este dom João Afonso foi o que trouxeram no atáude os infantes antes ditos e outros muitos bons

(002.XIII.0279-GOR)

d. Contexto: Como Galaaz entrou no paço e acabou a seeda [= cadeira] perigosa.

(...) - Rei Artur, eu te trago o cavaleiro desejado, aquei que vem do alto linhagem del-rei David e de Josep Baramatia, per que as maravilhas desta terra e das outras haverám cima.

E desto que o homem bõõ disse foi elrei mui ledo. $\mathrm{E}$ disse:

- Se esto é verdade, vós sejades bem viindo. E bem seja veúdo o cavaleiro, ca este é o que há-de dar cima aas aventuras do Santo Graal. Nunca foe feito em esta casa tanta honra, como lhe nós faremos. E quem quer que ele seja, eu querria que the veese muito bem pois de tam alto linhagem vem como vós dizedes. (...)
(... porque este é o que há de dar fim às aventuras do Santo Graal.) (004.XIII.0030-GON)

Então, não fugindo à gramaticalização que se evidencia numa tendência translinguística, nesse Estágio 2, a categoria ESPAÇO é conceptualizada por uma referência demonstrativa, intercalando a cópula ser e o que marcador da cláusula relativa. Como resultado de inferências de implicaturas conversacionais e da pressão de informatividade, aparece a construção é o que, mostrando um uso mais especializado e mais fixo do demonstrativo "o", que se refere ao sujeito da cláusula matriz, numa construção típica do que, atualmente, denominam "pseudo-clivada invertida". Ao usar a construção é o que em uma situação comunicativa, o falante sente a necessidade de fazer remissão ao ESPAÇO textual já mencionado, com o uso da referência demonstrativa "o" (e não mais o OBJETO), de modo a intensificar a informação para a qual ele quer chamar a atenção do ouvinte.

Estruturalmente, trata-se de uma construção de clivagem, mais gramatical (semânticosintaticamente), empregada para focalizar um elemento da cláusula matriz, a qual está bem mais integrada à cláusula relativa. Com base apenas nesse aspecto, a tendência translinguística de gramaticalização seria Demonstrativo > Foco, por meio da metáfora OBJETO > ESPAÇO > CONEXÃO TEXTUAL. Entretanto, semântico-pragmaticamente, a clivagem vem a serviço da ênfase que o falante imprime ao sinalizar o desejo de chamar a atenção do ouvinte para algo; e, para tanto, o falante insere um argumento (informação) em um argumento maior, objetivando economia e informatividade. Sendo assim, sugerimos, para dar conta da gramaticalização do é que, uma trajetória que também dê conta desses aspectos semântico-pragmáticos.

Com esse objetivo, optamos pela trajetória traçada por Traugott e König (1991, p. 208): Tendência I - Significados baseados na descrição da situação externa > Significados baseados na situação interna; Tendência II - Significados baseados na descrição da situação externa ou interna > 
Significados baseados na situação textual; Tendência III - Significados tendem a tornar-se cada vez mais situados nas crenças/atitudes subjetivas do falante com respeito à situação.

As Tendências semântico-pragmáticas I e II corresponderiam ao desenvolvimento da gramaticalização apresentada pelos Estágios 1 e 2. Com base nessa tendência, os dados do Português Antigo, do COMTELPO, parecem evidenciar a trajetória: significado concreto > significado textualdiscursivo no início da gramaticalização de é que; ou seja, segue o percurso: Hec est...q (Estágio 0 e 1) > é o que (Estágio 2), como mostra o Quadro 2, mais adiante.

Ainda nesse Estágio 2, há a reanálise do demonstrativo com o relativo, ou seja, os dois passam a ser reinterpretados por um "que" complementador (conjunção integrante), portanto mais gramatical. Nesse caso, aplica-se a tendência de gramaticalização: Demonstrativo > Complementador > Marcador de foco. Mas a função de marcação de foco incorpora o ser reanalisado, o complementador vem sempre depois da cópula, a qual concorda em número-pessoa com o sujeito da cláusula matriz e atende às mesmas restrições de tempo da cláusula complementadora. É o caso da construção de clivagem chamada de "pseudo-clivada invertida de é que" (COSTA; DUARTE, 2001) ou "construção É QUE" (BRAGA, 1989; LONGHIN, 1999).

Considerando a frequência da "construção É QUE” (de clivagem) no decorrer do tempo, a rotinização faz que ocorra uma generalização analógica por meio do padrão de uso (FRIES, 1940). Continuando seu fortalecimento pragmático, a pressão de informatividade e a convencionalização de inferências conversacionais fazem que a construção se torne mais contígua e assuma seu caráter de fórmula "é que", invariável, como um morfema não segmentável, funcionando não mais como um conector, mas sim como um "marcador de ênfase" presente em uma única cláusula.

O é que como marcador de ênfase vêm já desde os Séculos XIII e XIV, como em (8a), mas como uma construção de clivagem, cuja cópula ainda carrega a marca do tempo e concorda com o sujeito da frase matriz. A amostra (8b) flagra uma forma híbrida do "quem" (= o que > que), quando permite uma leitura ora de relativo ora de conjunção integrante, mostrando, assim, uma passagem de função.

(8) a. Contexto: O anjo e a alma em um lugar muito formoso

(...)e preguntou entõ ao angeo de quaes era aquella folgança? E o ango disse:

- He daqueles que receberõ marteiro por amor de Deus e por esso rrecebẽ tanta honra, como tu vees: outros som que uiuerom em castidade.

Entom olhou a alma a todas as partes e uio mujtos castellos e mujtas torres ...

( - É daqueles que receberam martírio por amor de Deus e por isso recebem tanta honra, como tu vês: outros são que viveram em castidade.

(001.XIV.0046-GON)

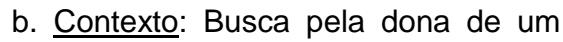
vestido

(...) Mas a dõzella porque luas roupas nam andalfem pola villa dando occaliam de algũa lospeita the diffe. Senhora le quereis vender efle veftido eu o comprarey. A labia dona a entendeo, e lho veo a dar muito barato, e lho veftir, como logo o veltio, e ficou com elle contente. E a dona foy dizer ao fidalgo a cala, e a pelloa que era quem Ihe deixou o veltido, porque como ella andou com aquellas roupas a mór parte da villa, achou o alfaiate que as fez, e outros finaes verdadeiros, verdadeira proua, q aquelle veftido era daquella donzella, e (...)

(...e a pessoa que era quem the deixou o vestido,...)

(001.XVI.0007-GON)

Contudo, constituindo o Estágio 3, é nos meados do Século XVII que a expressão é que já aparece resultante de reanálise, ou seja, usado formulaicamente com o "verbo" ser fixo no tempo presente do indicativo, sem marcas de concordância, e com o que funcionando não mais como conector; os dois constituem um morfema não segmentável. Acontece em uma posição medial de uma só frase (não há mais uma bipartição), depois do elemento a ser enfatizado e antecedendo o verbo. Na época, já havia significação epistêmica abstrata, mostrando a atitude de certeza do falante sobre aquela informação defendida e não outra, sugerindo, assim, um contexto contrastivo, como em (9). 
(9) Contexto: A verdade a cargo do pai do Reverendo Padre Frei Matheus da Conceição

(...) E porque sobretudo a informação $e$ uerdade de Vossa Paternidade he que ha de realçar esta nossa abonação e credito, pois Vossa Paternidade sabe tudo milhor que ninguem como quem tam particularmente em uida, e em morte assistio sempre ao Senhor Bispo, Peço muito a Vossa Paternidade nos queira fazer merce, e charidade querer declarar e dizer a uerdade do que se passa nesta materia

(005.XVII.0104-GOP)

Conforme a amostra (9), o Estágio 3 corresponde à tendência semântico-pragmática III, de Traugott e König (1991, p. 209), segundo a qual, "os significados tendem a tornar-se cada vez mais situados nas crenças/atitudes subjetivas do falante com respeito à situação". Esse estágio marca o estabelecimento da expressão é que com significação epistêmica relacionada à "realidade", "verdade". Esse significado epistêmico pode ser evidenciado, segundo o principio de persistência (HOPPER, 1991), por meio do étimo do verbo ser. Segundo Vendryès (1921), a raiz proto-indo-européia es "ser", que forneceu a cópula em data muito antiga, denota propriamente "a existência, a vida" e o demonstra através do particípio sat, que designa "um ser real" e o derivado satyas, "verdadeiro", e mediante o grego tà ónta, "a realidade". Então, a expressão é que enfatiza a atitude de certeza do falante para o ouvinte, buscando-a ou asseverando-a por meio de contraste. Esses dados sugerem, portanto, a definição do é que como um operador que assinala (enfatiza) um argumento, dando uma certeza epistêmica a uma determinada conclusão, e contrastando-o com conteúdo(s) pressuposto(s), ao qual denominamos marcador enfático-contrastivo.

Sintetizando, a mudança total para o marcador de ênfase é que se deu a partir da referência concreta para a expressão da avaliação do falante para marcar a relevância do que está sendo posto em saliência para uma avaliação do contraste pelo ouvinte. Demonstra, pois, uma mudança para uma construção mais abstrata e subjetiva do mundo em termos de linguagem, ou seja, a mudança sugere a tendência de uma cadeia do tipo: Construção lexical plena > Construção morfossintática (de clivagem) > Marcador discursivo

Vejamos, no Quadro 1, as etapas de gramaticalização da expressão é que, segundo os

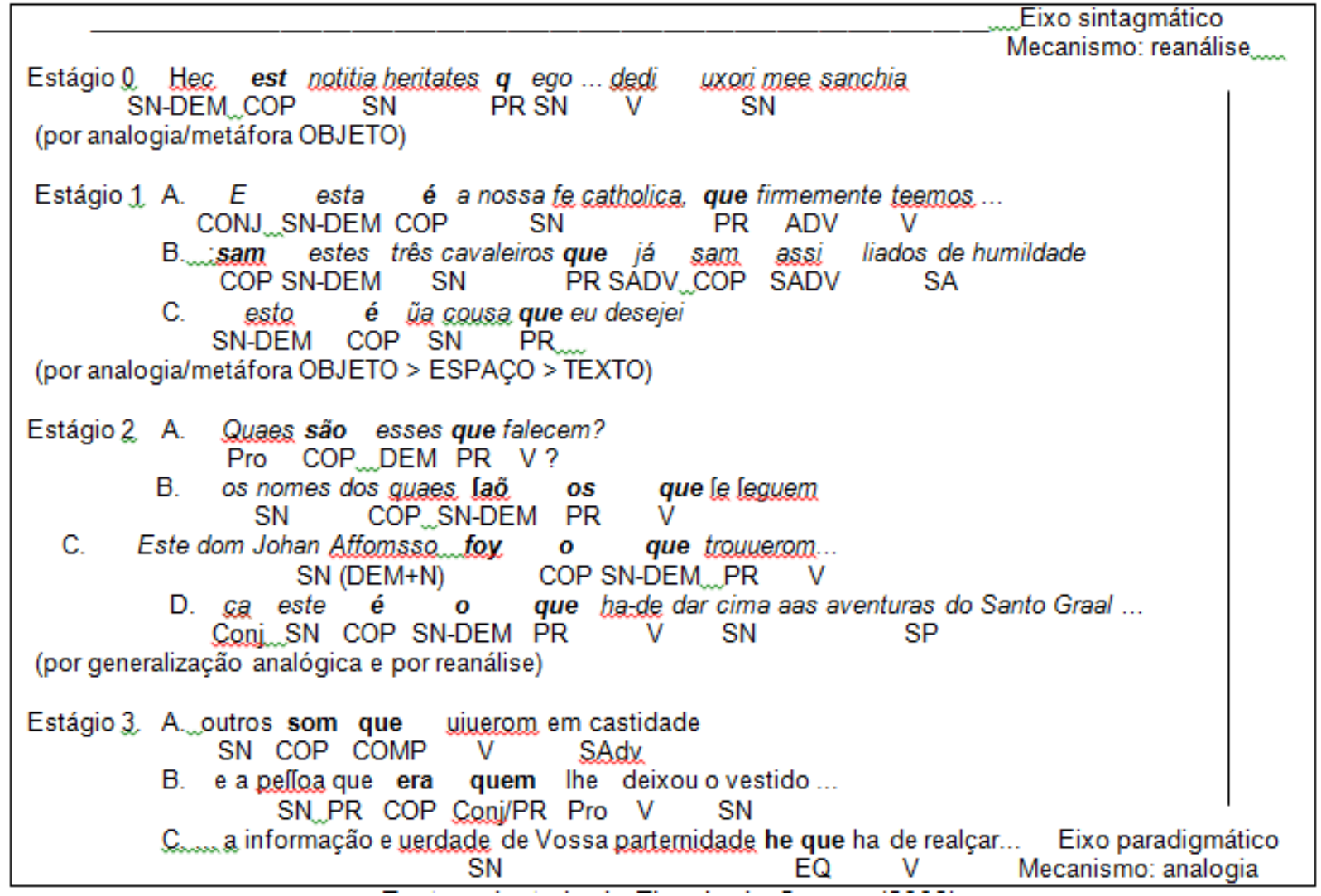


processos e mecanismos complementares envolvidos na mudança semântico-pragmática.

Como mostra o Quadro 1, a tendência de mudança envolve tanto o processo "metonímico" quanto o "metafórico", pondo em cheque a afirmação de Hopper e Traugott (2003, p. 39) de que a reanálise "é um pré-requisito para a implementação da mudança por meio da analogia", ou seja, a convencionalização das metonímias conceptuais se origina no fluxo sintagmático da fala que é a primeira motivação para a reanálise nos primeiros estágios ( $p$. 93). Essa tendência pode ser específica ao desenvolvimento do be going to. Conforme o desenvolvimento da expressão é que, tanto a metáfora e analogia quanto à metonímia e a reanálise são processos e mecanismos complementares na gramaticalização.

\section{Quadro 2: Gramaticalização da expressão é que}

Quadro 2: Gramaticalizaçào da expressào eque segundo as funçoes da linguagem

\begin{tabular}{|c|c|c|}
\hline Tendéncial & Tendencia ll & Tendencia III \\
\hline $\begin{array}{c}\text { Hec est_. } a \\
\text { Portuguess Antigo }\end{array}$ & $\begin{array}{c}\text { (Isto) é o que } \\
\text { Portugues Antigo }\end{array}$ & $\begin{array}{l}\text { é que } \\
\text { Pontuguess Clássico }\end{array}$ \\
\hline 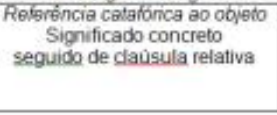 & $\begin{array}{l}\text { Rekeréncia anabrica ao objeto } \\
\text { Significado textual-discursivo } \\
\text { Relativo > Complementador de } \\
\text { clatusula }\end{array}$ & $\begin{array}{c}\text { Raferb́ncia reanalisada (implicta) } \\
\text { Significado epistemico (pragmatico. } \\
\text { discursivo) } \\
\text { presente em uma unica dausula } \\
\text { Complementador > Marcador de énfase }\end{array}$ \\
\hline
\end{tabular}

segundo as funções da linguagem.

Então, como mostra o Quadro 8, o falante marca a relevância da informação, por meio da expressão é que, colocando-a em saliência para uma avaliação do ouvinte. Esse último movimento caracteriza a função de chamar a atenção do ouvinte para algo, uma vez que, no processo interativo, entra em jogo a adequação do uso aos propósitos tanto do falante quanto do ouvinte. Essa relevância é, nesse estágio, marcada sem a referência demonstrativa, embora ela esteja implícita, para significar a crença/atitude do falante.

\section{Considerações finais}

Concluímos que o desenvolvimento do marcador de ênfase é que revela-se como o de muitos dos correlatos estruturais e pragmáticos unidirecionais que mudam normalmente associados à gramaticalização:

a) descategorização: o verbo ser, o pronome demonstrativo e o pronome relativo são reanalisados: há o apagamento do demonstrativo e os outros dois tornaram-se fixos.

b) vínculo dentro do sintagma: a fixação que acompanha a descategorização leva ao vínculo, ou seja, assume o caráter de fórmula "é que", invariável, como um morfema não segmentável, funcionando não mais como um conector, mas sim como um "marcador de ênfase" - presente em uma única cláusula.

c) generalização: Considerando a frequência da "construção É QUE" (de clivagem) no decorrer do tempo, a rotinização faz que ocorra uma generalização analógica por meio do padrão de uso.

d) fortalecimento pragmático: a pressão de informatividade e a convencionalização de inferências conversacionais fazem que a construção se torne mais contígua: Hec est (SN) q (significado concreto) > é o que (significado textual-discursivo) > é que (significado pragmático-discursivo), ilustra, pois, o movimento unidirecional que parte da referência concreta para a expressão da avaliação do falante para marcar a relevância do que está sendo posto em saliência para uma avaliação do contraste pelo ouvinte, do concreto para o abstrato.

e) subjetividade: o uso da expressão é que ocorre como uma das manifestações do grau de certeza, positiva ou negativa. Ou seja, o marcador de ênfase é que também expressa uma atitude do falante em relação à proposição, que corrobora o caráter multifuncional da expressão é que: marcador de ênfase e marcador epistêmico de asseveração, que se realiza como o que denominamos como marcador enfático-contrastivo.

\section{Referências}

BRAGA, M. L. As sentenças clivadas no português falado do Rio de Janeiro. Relatório apresentado ao CNPq. Rio de Janeiro, 1989 (mimeo). 
BUENO DE SEQUEIRA, F. M. A ação da analogia no português. Rio de Janeiro: Organizações Simões, 1954.

BYBEE, J. L.; PERKINS, R.; PAGLIUCA, W. The evolution of grammar: tense, aspect, and modality in the languages of the world. Chicago: University of Chicago Press, 1994.

CEZARIO, M. M.; GOMES, R; PINTO, D. Integração de cláusulas e gramaticalização. In:

MARTELOTTA, M. E.; VOTRE, S. J.; CEZARIO, M. M. Gramaticalização no português do Brasil: uma abordagem funcionalista. Rio de Janeiro: Tempo Brasileiro/UFRJ, 1996.

CLAUDI, U.; HEINE, B. On the metaphorical base of grammar. Studies in language 10, 1986.

COSTA, J.; DUARTE, I. Minimizando a estrutura: uma análise unificada das construções de clivagem em português. Actas do XVI Encontro Nacional da Associação Portuguesa de Linguística. Lisboa: Colibri, 2001. p. 62738.

FIGUEIREDO-GOMES, J. B.; PENA-FERREIRA, E. (Orgs.) Corpus mínimo de textos da língua portuguesa - COMTELPO. Lisboa: Faculdade de Letras da Universidade de Lisboa/PDEE/CAPES, 2006. (mimeo)

FRIES, C. C. On the development of the structural use of word-order in Modern English. Language,16, 1940. p. 199-208.

GIVÓN, T. On Understanding Grammar. New York: Academic Press, 1979.

GREEN, G. M. Pragmatics and natural language understanding, 2nd ed., Mahwah, NJ: Erlbaum, [1989]1996

HEINE, B.; CLAUDI, U.; HUNNEMEYER, F. Grammaticalization: a conceptual framework. Chicago: The University of Chicago Press, 1991.

HEINE, B.; REH, M. Grammatical categories in African languages. Hamburgo: Helmut Buske, 1984.

HOPPER, P. J. On some principles of grammaticalization. In: TRAUGOTT, E. C.; HEINE, B. (eds.) Approaches to grammaticalization. Vol. I. Amsterdam: Benjamins, 1991.

JOHNSON, M. The body in the mind: the bodily basis of meaning, imagination and reason. Chigago: The University of Chicago Press, 1987.
LAKOFF, G. Women, fire and dangerous things: what categories reveal about mind. Chicago: The University of Chicago Press. [1980], 1987.

LASS, R. On explaining language change. Cambridge, UK: Cambridge University Press, 1980.

LEVINSON, S. C. Presumptive meanings: the theory of generalized conversational implicature. Cambridge, MA: MIT Press, Bradford Book, 2000.

LONGHIN, S. R. As construções clivadas: uma abordagem diacrônica. 1999. Dissertação (Mestrado) - Universidade de Campinas, Campinas/SP, 1999.

NIE, N. H.; HULL, C.; BENT, D. H. SPSS Inc. http://www.spss.com ([1968] 2007.

SPERBER, D.; WILSON, D. Relevance, communication and cognition, 2nd ed. Cambridge: MA: Harvard University Press, [1951]1986.

WEETSER, E. From etymology to pragmatics. Metaphorical and cultural aspect of semantic structure. CUP Studies in Linguistics 54, 1990.

TRAUGOTT, E. C. Legitimate counter examples to unidirecionality. Paper Presented at Freiburg University, Octuber 17th 2001.

TRAUGOTT, E. C.; HOPPER, P. J. Grammaticalization. 2ed. Cambridge: Cambridge University Press, 2003.

TRAUGOTT, E. C.; KÖNIG, E. The semanticspragmatics of grammaticalization reviseted. In: TRAUGOTT, Elizabeth C.; HEINE, Bernd. (eds.) Approaches to grammaticalization. Focus on theoretical and methodological issues. Vol.I Amsterdam: Benjamins, 1991.

VENDRYÈS, J. Le langage. Paris: Berne, [1921] 1950. 